\title{
DURABILITY AND MECHANICAL PROPERTIES OF ROLLER COMPACTED CONCRETE CONTAINING COARSE RECLAIMED ASPHALT PAVEMENT
}

\section{ALIREZA MAHDAVI, ABOLFAZL MOHAMMADZADEH MOGHADDAM*, MOHAMMAD DAREYNI \\ Department of Civil Engineering, Ferdowsi University of Mashhad, Mashhad, Iran}

Received 17 August 2020; accepted 15 April 2021

\begin{abstract}
The feasibility of utilizing Reclaimed Asphalt Pavement (RAP) as a replacement for coarse aggregates in Roller Compacted Concretes (RCCs) was assessed. This replacement was performed in different volumetric percentages $(25 \%, 50 \%, 75 \%$, and $100 \%)$. During this process, RAP materials were subject to abrasion and impact in the Los Angeles drum and mixer before being added to the mixture. Compressive strength, splitting tensile strength, flexural strength, crack propagation, Ultrasonic Pulse Velocity (UPV), electrical resistivity, density, and water absorption (in 7, 28, and 90 days of age) tests were done on all mixtures. Results show that utilizing RAP in RCC can cause a drop in the mechanical properties, but it has positive effects on crack propagation of the specimens due to their increased toughness. Increasing the amount of RAP in the mixtures has increased their electrical resistivity, likely owing to the hydrophobic properties of RAP, which causes prevention from connecting pores
\end{abstract}

* Corresponding author. E-mail: ab-moghadam@um.ac.ir

Alireza MAHDAVI (ORCID ID 0000-0002-1073-0088)

Abolfazl Mohammadzadeh MOGHADDAM (ORCID ID 0000-0001-6211-3738)

Mohammad DAREYNI (ORCID ID 0000-0002-0357-7193)

Copyright (C) 2021 The Author(s). Published by RTU Press

This is an Open Access article distributed under the terms of the Creative Commons Attribution License (http://creativecommons.org/licenses/by/4.0/), which permits unrestricted use,

distribution, and reproduction in any medium, provided the original author and source are credited. 
to each other. The relationship between the mechanical properties and UPV of the mixtures was analysed using regression models. Moreover, one- and twoway ANOVA (analysis of variance) tests were performed on the results at a 95\% confidence level. Finally, replacing the coarse aggregates with RAP only up to $75 \%$ is suggested if pre-processing is performed.

Keywords: crack propagation, electrical resistivity, mechanical properties, preprocessed reclaimed asphalt pavement; Roller Compacted Concrete, Ultrasonic Pulse Velocity.

\section{Introduction}

Nowadays, utilizing waste materials in the construction of road pavement is increasing, and there are positive reports regarding their performance. Waste materials are classified into two general categories: (i) recycled materials and (ii) industrial by-products, each including different materials. One of the most valuable recycled materials with pavement applications is RAP, which is produced in millions of tons in different countries annually. RAP is produced during the maintenance and rehabilitation phases of highways by milling and powdering the old asphalt surfaces and can be employed in different highway applications. RAP materials can be utilized as backfill, base and sub-base course materials, and in manufacturing different concrete and asphalt mixtures. Due to the presence of asphalt in RAP and the quality of its aggregates, it is less frequently used as backfill materials and is mainly utilized for manufacturing different asphalt mixtures. Utilizing RAP for asphalt mixture manufacturing is done by either in-place recycling or central plant recycling, which themselves can be performed in either cold or warm procedure (Jamshidi et al., 2012; Kar et al., 2018; Kriz et al., 2014; Mathias et al., 2009; Niazi and Jalili, 2009; Rahman et al., 2014; Saberi.K et al., 2017; Stroup-Gardiner, 2013; Xie et al., 2017; Yan et al., 2019). Replacing RAP for aggregates in concrete mixtures is another application of RAP. There have been several studies, all of which have two general results in common, firstly, using RAP as a replacement for aggregates causes the mechanical properties of the mixture to drop, and, secondly, replacing coarse aggregates leads to lower strength drops compared with replacing fine aggregates (Abdel-Mohti et al., 2016; Erdem and Blankson, 2014; Huang et al., 2005; Khodair and Luqman, 2017; Khodair and Raza, 2017; Shi et al., 2017; Singh et al., 2017; Singh et al., 2018).

Among all types of concrete mixtures, which have specific characteristics proportionate to their application, RCC is known to be a new technology that has drawn attention in roadway paving. In recent years, several major projects have been executed in North America 
using RCC, which has shown proper performance in the years being utilized. Also, RCC is increasingly drawing attention in Europe and Australia. The construction method of RCC pavements has benefits, including increased placement speed and reduced execution costs. These advantages are especially significant compared to conventionally constructed concrete pavements since RCC pavements do not use dowels, steel reinforcement and forms. Although the application of this type of pavement is extensive nowadays and includes various applications (e.g., log sorting yards, parking areas, lumber storage, municipal streets, and secondary highways), the first application of RCC was in Sweden in 1930 (ACI, 1995). RCC pavement is classified in the Jointed Plain Concrete Pavement (JPCP) category and is very different from the conventionally constructed concrete pavement in terms of fresh properties and construction method. This difference is associated with aggregate grading and mixing proportions since the amount of fine aggregates are relatively higher in RCCs and a water-to-cement ratio is lower, which leads to lower slump and higher stiffness (and consequently, different execution method) in RCCs (Harrington et al., 2010). Using RAP as a replacement for aggregates in RCC is one of the highway applications of RAP, on which some studies have been conducted. In the following, the results of these studies are described.

K. Bilodeau et al. have evaluated the effects of RAP as aggregates on the mechanical properties of RCC mixtures. They also made efforts to minimise the strength drop of mixtures by utilizing steel fibers. In this research, coarse aggregates were replaced by RAP in 40 and $80 \%$, and compressive strength, tensile strength, and compressive modulus of elasticity tests were performed on the mixtures. Results showed that increasing the amount of RAP in the mixtures led to higher drops in the mechanical properties. Also, assessments on the complex modulus of elasticity of the mixtures in different temperatures and frequencies revealed that adding RAP caused an increase in the sensitivity of the mixtures to the temperature and loading frequency, such that decreasing the temperature and increasing the loading frequency caused the complex modulus of elasticity to increase, in the RCC mixtures containing RAP (Bilodeau et al., 2011).

Ferrebee et al. evaluated the mechanical and fracture properties of the RCC mixtures by replacing $16 \%$ of aggregates with RAP. Results of this research indicated that the compressive and tensile strength of the mixture containing RAP decreased by $27 \%$ and $16 \%$, respectively. The width of the bottom crack in the beam under cyclic loading was also investigated to evaluate the fracture properties of the mixtures, which indicated an increase in the width of the crack. Also, more accurate investigations on the fracture properties of the mixtures revealed that 
using RAP caused drops in the initial fracture energy, resistance to Mohammad Dareyni cracking, and total fracture energy of the mixtures (Ferrebee et al., 2014).

Utilizing supplementary cementitious materials alongside replacing aggregates with RAP can result in favourable environmental properties. To this end, Modarres and Hosseini assessed RCC mixtures containing RAP (as a replacement for a portion of aggregates) and rice husk ash (as a replacement for a portion of cement). Three scenarios were considered in this research, including using rap as a replacement for (1) fine aggregate, (2) coarse aggregate, and (3) the whole aggregates. Moreover, the compressive and flexural strength, toughness, and fatigue of the mixtures were measured, which revealed drops in mechanical properties and fatigue life of all mixtures containing RAP. Results indicated that the mixtures containing RAP as a replacement for both fine and coarse aggregates showed the highest drop in the mechanical properties and fatigue life, while the lowest drop in these characteristics was associated with mixtures containing coarse RAP. Although using RAP caused a drop in the mechanical properties and fatigue life of the mixtures, the toughness of the mixtures showed an increasing trend which was due to the increased amount of displacements before fracture of the specimens containing RAP. According to moisture-density curves, it can be observed that using RAP not only decreases the optimum moisture but also decreases the density of the mixtures (Modarres and Hosseini, 2014).

Unlike other studies in this field, Settari et al. reported that utilizing RAP as fine aggregates could result in RCC mixtures with better performance compared with mixtures containing coarse RAP. In this research, RAP replacement was performed in different parts of aggregates (as 100\% of fine aggregates, 100\% of coarse aggregates, $100 \%$ of whole aggregates, and $50 \%$ of whole aggregates), and the mechanical properties of the mixtures were evaluated. This showed that the best performance was associated with the mixture containing $50 \%$ RAP, among all mixtures. Although mechanical properties of the mixtures containing RAP showed a drop compared with the control mixture but using $50 \%$ of RAP significantly enhanced the capillary water absorption of the mixture compared with the control mixture (Settari et al., 2015).

Fakhri and Amoosoltani utilized RAP and crumb rubber as a replacement for a portion of aggregates in RCC mixtures and evaluated the effects of these two recycled materials on the mechanical properties. In this research, mixtures were manufactured with different amounts of cement (from 250 to $400 \mathrm{~kg} / \mathrm{m}^{3}$ ) and different aggregates gradings, and their compressive and flexural strengths, toughness, energy 
absorption, modulus of elasticity and stiffness were tested. Results of the compressive strength test showed that the grading of aggregates had a considerable effect on the test results, such that, by using gradings with lower fineness modulus, higher percentages of aggregates could be replaced by RAP. By comparing the mechanical properties of the mixtures containing $25 \%$ RAP and $25 \%$ crumb rubber, it was evident that the mixtures containing RAP showed lower drops in the mechanical properties compared with mixtures containing crumb rubber. Unlike RAP materials, which reduce the compressive and flexural strengths of the mixtures, using $5 \%$ crumb rubber led to a small improvement in the compressive strength. Load-displacement curves showed that utilizing RAP in the mixtures caused the amount of energy absorption and toughness of the mixtures to increase, which meant their ductility was increased (Fakhri and Amoosoltani, 2017). As mentioned before, using RAP as a replacement for a portion of aggregates causes the mechanical properties of the mixtures to drop. This strength drop will be minimized if RAP is used as a replacement for coarse aggregates. The main reason for the strength drop in the mixtures containing RAP is the weak adhesion between the cement paste and the aged asphalt layer around RAP materials (Fakhri and Amoosoltani, 2017). A method to deal with this weakness in these mixtures is to perform pre-processing on RAP materials. Al-Mufti and Fried suggested roughening by mixers as a solution. According to their research, roughening RAP materials in the mixer up to 2 hours can lead to small strength improvement for the mixtures, while increasing the roughening duration to 3 hours will cause no strength drop in them (Al-Mufti and Fried, 2017).

This study was aimed to evaluate the effects of coarse RAP materials as an alternative to the coarse aggregates on the mechanical and durability properties of roller concrete mixes. To improve the quality of RAP aggregates, these materials were subjected to pre-processing before being used in the concrete. Then, mixtures containing RAP materials were assessed by mechanical experiments, and, using nondestructive ultrasonic and electrical resistivity tests on all specimens, regression models were developed for each mechanical property of the mixtures. Also, the effect of RAP materials on crack propagation speed in specimens under loading was investigated through a crack propagation test. 


\section{Materials and methods}

\subsection{Materials and mixture proportioning}

In this research, cement, water, aggregates and RAP were used to manufacture the mixtures. Regarding the design strength, the cement amount was chosen to be $16 \%$ of the dry aggregate mass. The cement used in this research is type-II cement obtained from the Zaveh factory located in Torbat, Iran, which is moderate resistant against sulphate attacks, and its mechanical, physical and chemical properties are as shown in Table 1.

Table 1. Mechanical, physical and chemical properties of the cement

\begin{tabular}{ccccc}
\hline \multicolumn{2}{c}{$\begin{array}{c}\text { Chemical properties } \\
\text { Oxide, \% }\end{array}$} & \multicolumn{4}{c}{$\begin{array}{c}\text { Mechanical and physical properties } \\
\text { Properties }\end{array}$} \\
\hline $\mathrm{SiO}_{2}$ & 21.4 & Compressive strength, $\mathrm{MPa}$ & 3 Day & 19 \\
$\mathrm{Al}_{2} \mathrm{O}_{3}$ & 4.95 & - & 7 Day & 34 \\
$\mathrm{Fe}_{2} \mathrm{O}_{3}$ & 3.91 & - & 28 Day & 52.5 \\
$\mathrm{CaO}$ & 63.5 & Specific gravity & - & 3.02 \\
$\mathrm{MgO}$ & 2.6 & Blaine specific surface, cm ${ }^{2} / \mathrm{g}$ & - & 2900 \\
$\mathrm{Na}_{2} \mathrm{O}$ & 0.4 & Initial setting time, min & - & 90 \\
$\mathrm{~K}_{2} \mathrm{O}$ & 0.55 & Final setting time, min & - & 170 \\
$\mathrm{SO}_{3}$ & 1.3 & Autoclave expansion, \% & - & 0.15 \\
L.O.I (max) & 0.9 & - & - & - \\
I.R (max) & 0.25 & - & - & - \\
\hline
\end{tabular}

The proper mixture gradation was obtained by combining two natural coarse aggregate borrow pit with one natural fine aggregate borrow pit (Fig. 1). As shown in Table 2, due to lower density of RAP materials compared with the natural aggregates, the aggregate replacement with RAP was done in different volumetric percentages (25\%, 50\%, $75 \%$ and $100 \%)$. To acquire the mixture proportioning based on Modified Proctor Method, optimum moisture was measured for each of the mixtures, and mixing proportions were obtained based on volumetric relationships. Figure 2 shows the optimum moisture curves, and Table 3 presents the mixing proportions for each mixture. It can be seen that by increasing the amount of RAP, optimum moisture and maximum dry density of the mixtures were decreased.
Mohammad Dareyni

Durability and Mechanical Properties of Roller Compacted Concrete Containing Coarse Reclaimed Asphalt Pavement 
Table 2. Properties of the aggregates and RAP used in this research

\begin{tabular}{|c|c|c|c|c|c|c|c|c|}
\hline \multirow[b]{2}{*}{ Source } & \multicolumn{3}{|c|}{ Specific Gravity } & \multirow{2}{*}{$\begin{array}{l}\text { Absorp- } \\
\text { tion, \% }\end{array}$} & \multirow{2}{*}{$\begin{array}{c}\text { Fractured } \\
\text { Particle, } \\
\%\end{array}$} & \multirow{2}{*}{$\begin{array}{c}\text { Sand } \\
\text { Equivalent, } \\
\%\end{array}$} & \multicolumn{2}{|c|}{$\begin{array}{c}\text { Effective bitumen } \\
\text { content, } \%\end{array}$} \\
\hline & Dry & SSD & Apparent & & & & $\begin{array}{c}\text { Before } \\
\text { pro- } \\
\text { cessing }\end{array}$ & $\begin{array}{l}\text { After } \\
\text { pro- } \\
\text { cessing }\end{array}$ \\
\hline $\begin{array}{c}\text { Natural } \\
\text { Coarse } \\
\text { Aggregate }_{1}\end{array}$ & 2.645 & 2.681 & 2.743 & 1.35 & 95 & - & - & - \\
\hline $\begin{array}{c}\text { Coarse } \\
\text { Aggregate }_{2}\end{array}$ & 2.601 & 2.652 & 2.741 & 1.97 & 95 & - & - & - \\
\hline $\begin{array}{c}\text { Fine } \\
\text { Aggregate }\end{array}$ & 2.576 & 2.649 & 2.780 & 2.86 & - & 68 & - & - \\
\hline $\begin{array}{c}\text { Coarse } \\
\text { RAP (After } \\
\text { processing) }\end{array}$ & 2.38 & 2.4 & 2.43 & 0.89 & - & - & 3.53 & 3.11 \\
\hline
\end{tabular}

Table 3. Mixing proportions for all mixtures

\begin{tabular}{cccccccccc}
\hline \multirow{2}{*}{ Mix. } & \multirow{2}{*}{ w/c } & \multicolumn{3}{c}{ Aggregates, $\mathbf{k g} / \mathbf{m}^{\mathbf{3}}$} & \multicolumn{3}{c}{ RAP, $\mathbf{k g} / \mathbf{m}^{\mathbf{3}}$} & \multirow{2}{*}{ Cement } & Water \\
\cline { 3 - 8 } & & Fine & Coarse $_{1}$ & Coarse $_{2}$ & 4\# & $\mathbf{3 / 8 \#}$ & $\mathbf{1 / 2 \#}$ & & \\
\hline R0 & 0.45 & 1307.7 & 538.4 & 76.9 & 0.0 & 0.0 & 0.0 & 307.7 & 137.4 \\
R25 & 0.43 & 1315.3 & 406.2 & 58.0 & 28.7 & 55.3 & 55.2 & 307.1 & 133.4 \\
R50 & 0.43 & 1320.2 & 271.8 & 38.8 & 57.6 & 111.1 & 110.8 & 305.8 & 131.1 \\
R75 & 0.41 & 1329.5 & 136.9 & 19.6 & 87.0 & 167.8 & 167.3 & 305.5 & 126.0 \\
R100 & 0.40 & 1338.0 & 0.0 & 0.0 & 116.8 & 225.2 & 224.5 & 305.0 & 121.4 \\
\hline
\end{tabular}

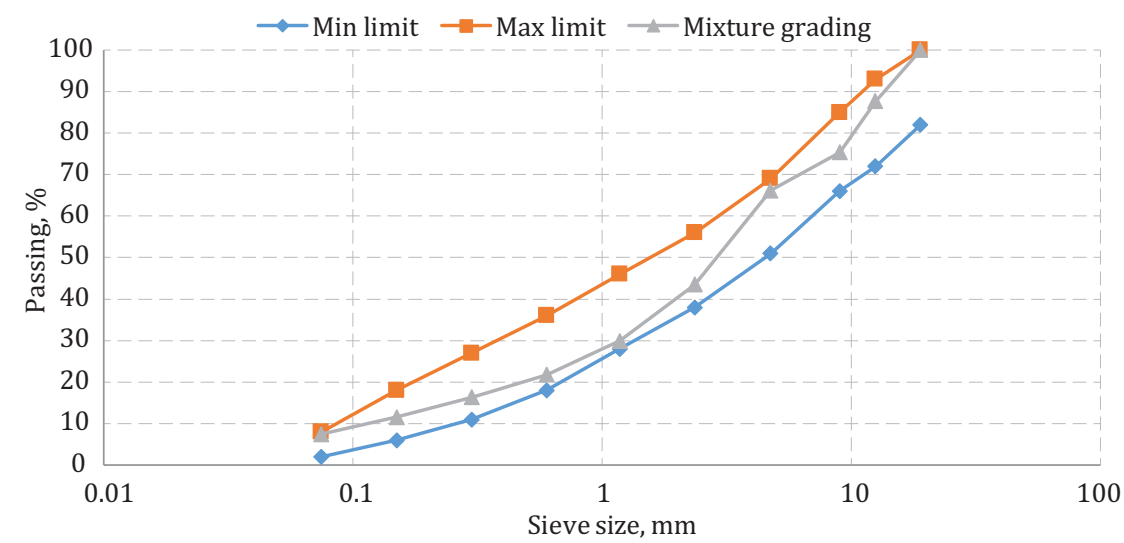

Figure 1. Blended aggregate gradation and allowable limits based on $\mathrm{ACI} 211.3$ 


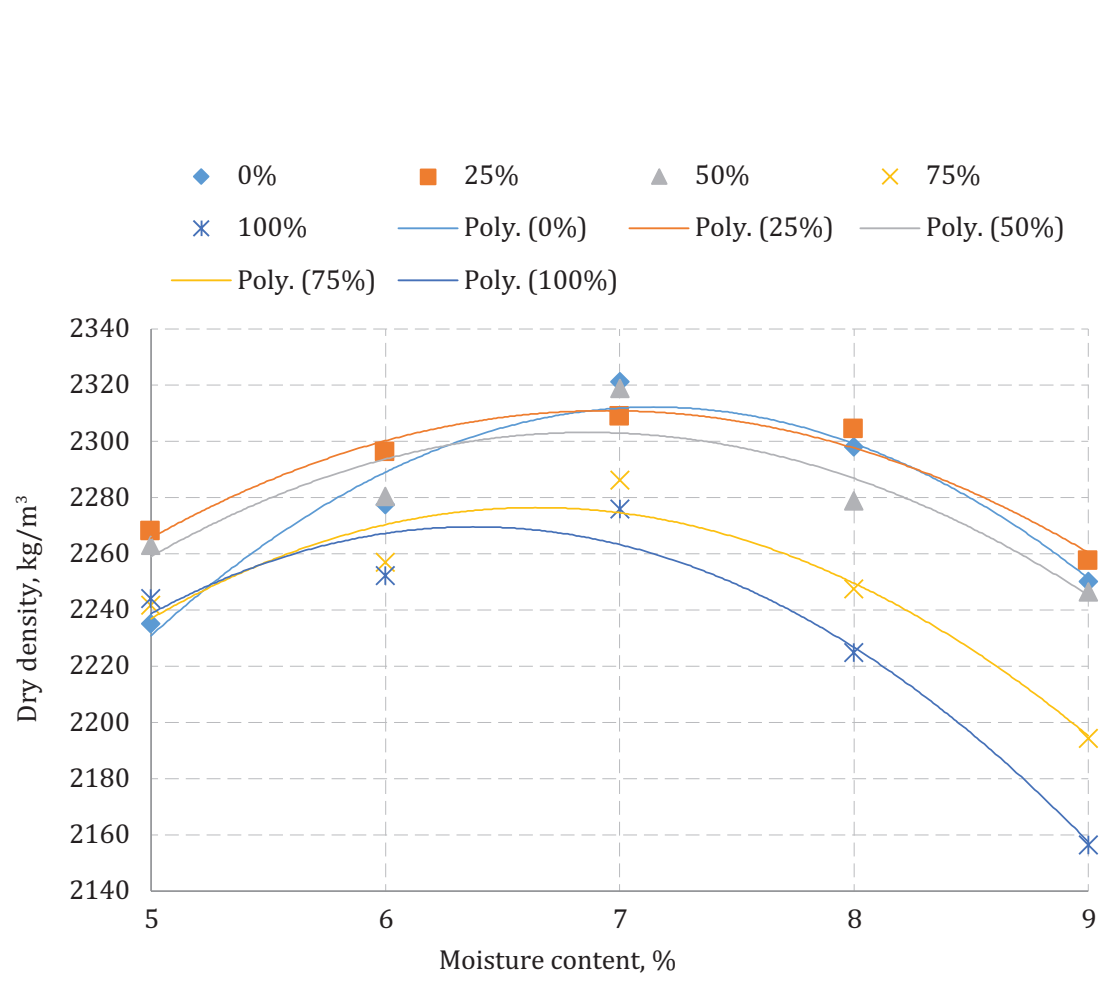

Figure 2. Optimum moisture curve of each mixture

\subsection{RAP pre-processing}

In this study, to crumble the lumps and weak layers around RAP materials, pre-processing operations were accomplished. Since the treatment methods of RAP presented in the earlier study (Al-Mufti and Fried, 2017) are time-consuming, in order to save time, this operation was performed with higher intensity. To this end, RAP materials were placed under impact and abrasion (Fig. 3) in the Los Angeles machine (having 12 steel spheres) and the Horizontal mixer (100 litres), respectively, for a particular duration. These devices were employed for the pre-processing purpose to subject materials to abrasion (in the mixer) and impact (in the Los Angeles drum). The optimal preprocessing limit is defined as a time duration after which the change in gradation of the RAP materials remains negligible. Aiming to recognise the optimal pre-processing time, RAP materials with a specific gradation were subject to abrasion and impact by the Los Angeles machine and mixer. The pre-processing was implemented in the Los Angeles machine for 1-minute and 1.5-minute time steps, and the gradation was determined after each step (Fig. 4). After six abrasion steps, the same materials were placed inside the mixer for 2-minute and 4-minute 
time steps, and their gradation was determined afterward. Finally, percentages of the material gradation variation in the $j^{\text {th }}$ step compared with $(j-1)^{\text {th }}$ step were calculated using Eqs. (1) \& (2).

$$
\begin{gathered}
A_{j}=\frac{\sum_{i=1}^{n} \frac{P_{i 0}-P_{i j}}{P_{i 0}} \times 100}{n} \\
\Delta_{j}=A_{j}-A_{j-1}
\end{gathered}
$$

In this equation, $P_{i j}$ is the percentage remaining on $i^{\text {th }}$ sieve size in the $j^{\text {th }}$ step $(j=0$ denotes the moment before beginning abrasion and impact), $n$ is the number of standard sieves, $A_{j}$ is the gradation variation percentage after step $j$ compared with the initial gradation, and, $\Delta_{j}$ represents the gradation variation percentage after the $j^{\text {th }}$ step compared with the $(j-1)^{\text {th }}$ step. In this research, the duration of preprocessing was chosen such that either the variation percentage on that step was less than $2 \%$ or the paired t-test of two successive steps for gradation became insignificant (i.e., there was no significant difference between two gradations at $90 \%$ confidence level; $p$-value $>0.1$ ). These
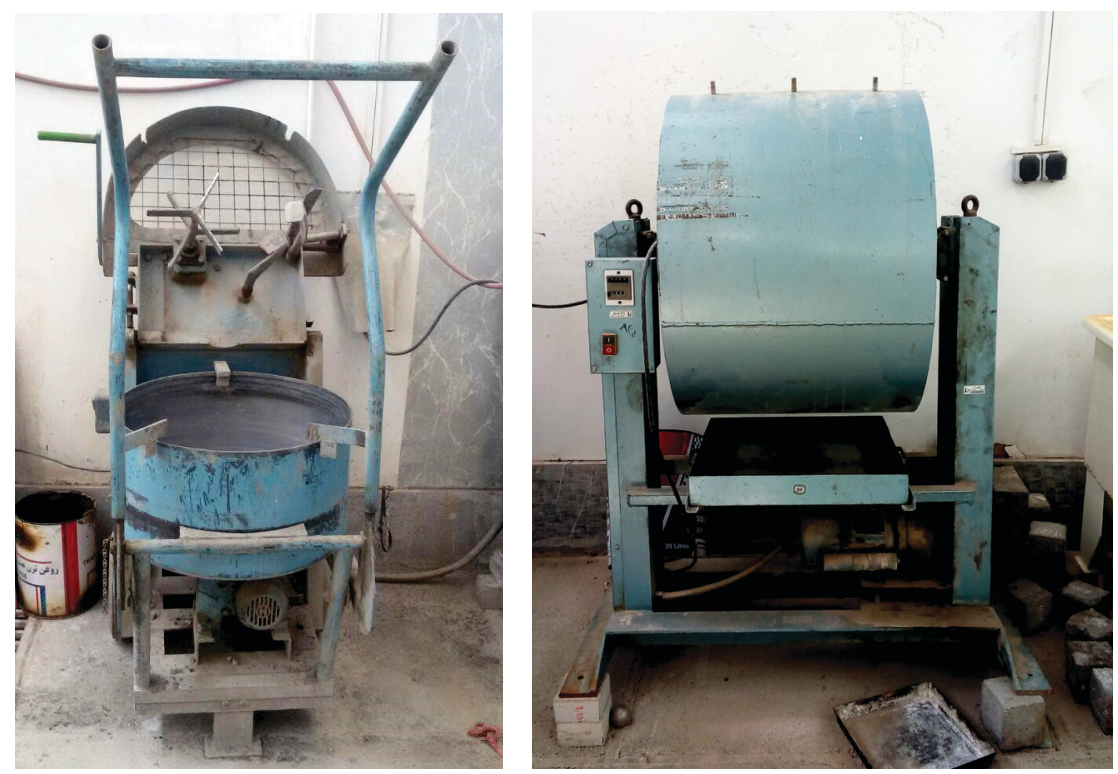

Figure 3. The Los Angeles machine (right) and the mixer (left) used for pre-processing 
criteria were adopted based on the maximum allowable tolerances Mohammad Dareyni of gradation from Iran's General Technical Specifications of the Road. Therefore, using Eqs. (1) and (2) and statistical test, the optimal preprocessing time for the RAP materials inside the mixer and the Los Angeles machine was obtained as 12 and 5 minutes, respectively. This means that RAP materials were processed in a mixer and Los Angeles for 12 and 5 minutes, respectively, before being used to make the mixtures.

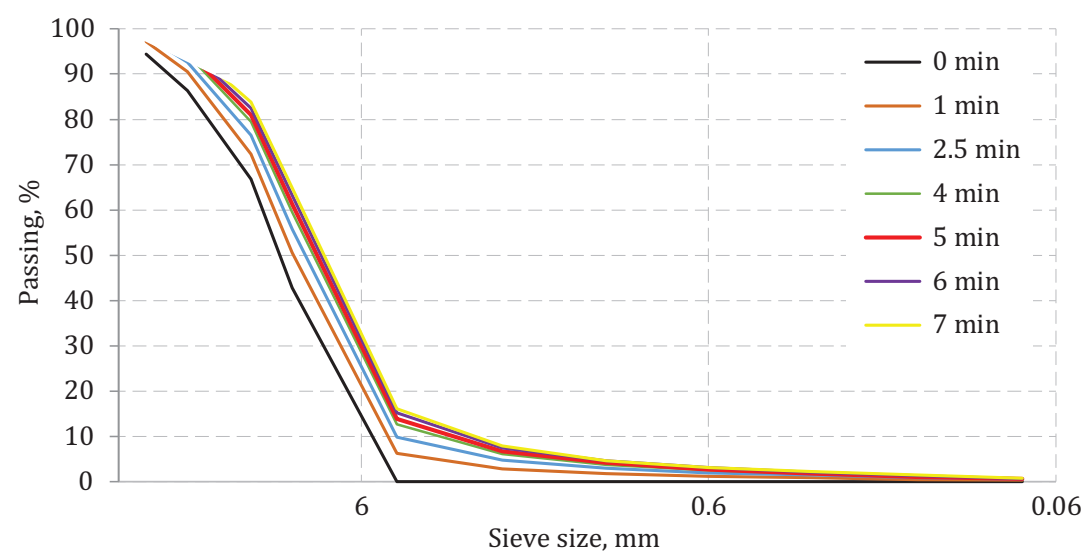

Figure 4. Gradation of RAP aggregates after each step of processing in the Los Angles machine

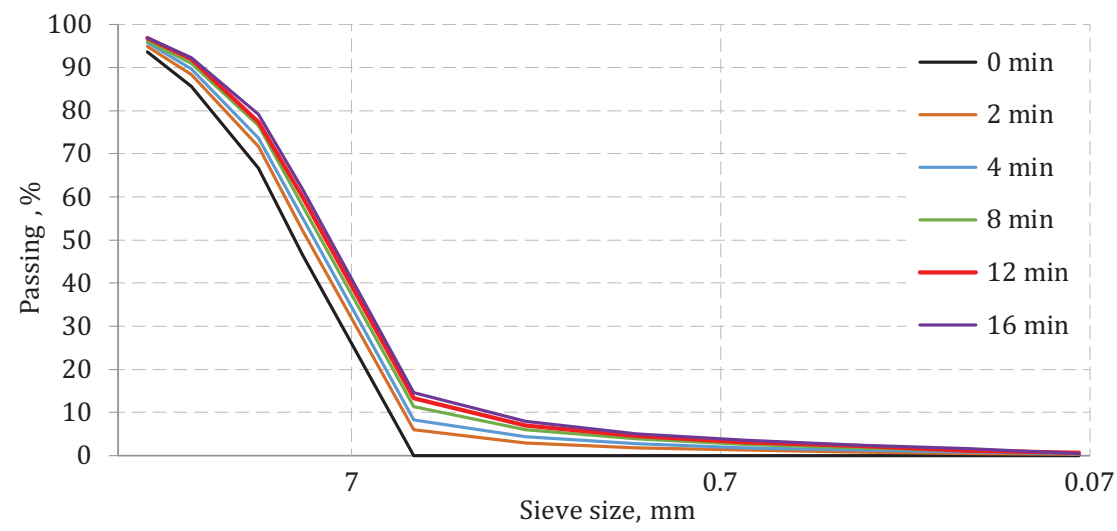

Figure 5. Gradation of RAP aggregates after each step of processing in the mixer 


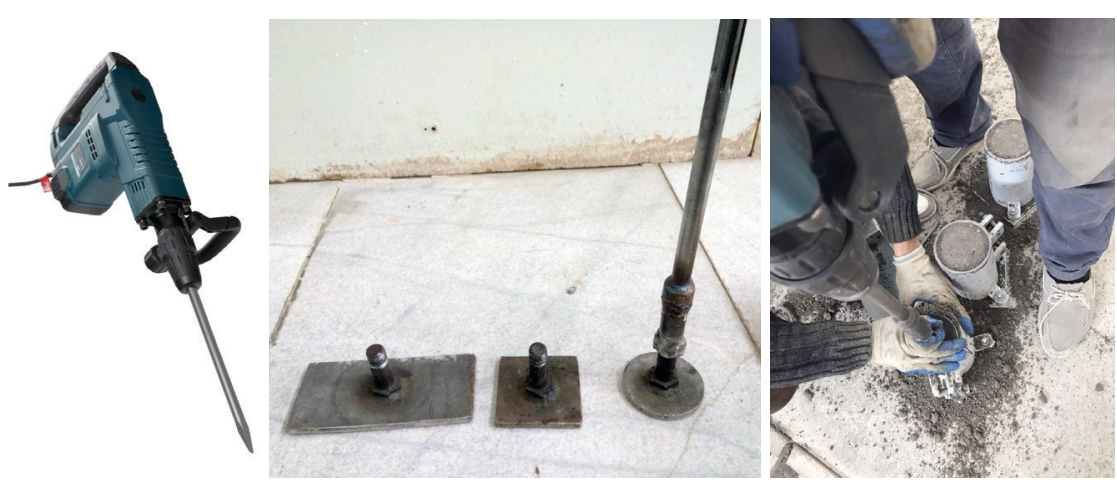

Figure 6. Vibrating hammer (right), plates (middle), and specimen compaction method (left)

\subsection{Specimen manufacturing and curing}

To manufacture the required specimens, three types of moulds were used, including the cubic moulds with $100 \mathrm{~mm} \times 100 \mathrm{~mm} \times 100 \mathrm{~mm}$ dimensions, cylindrical moulds with $200 \mathrm{~mm} \times 100 \mathrm{~mm}$ dimensions, and beams with $400 \mathrm{~mm} \times 100 \mathrm{~mm} \times 100 \mathrm{~mm}$. These specimens were manufactured utilizing a vibrating hammer shown in Fig. 6 and according to ASTM C1435 (cylindrical specimens were compacted in four layers, and cubic specimens were compacted in three layers). After 24 hours from the compaction time, the specimens were demoulded and were cured for 7, 28 and 90 days in immersed conditions, and then the tests were performed.

\subsection{Test method}

\subsubsection{Compressive strength}

The compressive strength test was performed in accordance with BS EN 12390-3:2002 on the cubic specimens, with a $3 \mathrm{kN} / \mathrm{s}$ loading speed, which was equivalent to a $0.3 \mathrm{MPa} / \mathrm{s}$ stress increment. In this research, three specimens were tested for each mixture at 7,28 and 90 days of age, in saturated surface dry condition.

\subsubsection{Flexural strength}

The flexural strength of the mixtures used for pavement purposes is of substantial importance, and design methods are usually based on this characteristic of the concrete. In this research, in accordance with ASTM 
C78/C78M-15b, the loads were applied to the third points. To perform this test at each age, three beam specimens were used in the saturated surface dry condition. The loads were applied with a $0.055 \mathrm{kN} / \mathrm{s}$ speed (equivalent to $1 \mathrm{MPa} / \mathrm{min}$ increase in tensile stress in the bottom fibre of the beam) at $100 \mathrm{~mm}$ distance from the supports.

\subsubsection{Splitting tensile strength}

The tensile strength of the mixtures was measured indirectly using cylindrical specimens. This test was also performed in accordance with ASTM C496/C496M - 11 on saturated specimen with dry surface. The loads were applied with a $0.52 \mathrm{kN} / \mathrm{s}$ speed equivalent to a $1 \mathrm{MPa} / \mathrm{min}$ increment in the tensile stress of the loaded surface.

\subsubsection{Ultrasonic pulse velocity}

Ultrasonic test is known to be the most common non-destructive test for concrete, and its applications are developing in quality control of different materials. This test is based on propagating ultrasonic pulse and measuring its velocity in the length of the specimen. Passing velocity of the ultrasonic pulse in a concrete specimen is a criterion for assessing the quality of the mixture since this characteristic is affected by density, dynamic Poisson's ratio, dynamic modulus of elasticity, porosity, moisture, segregation, curing duration, water-to-cement ratio and mixture proportions in general. In this research, Portable Ultrasonic Non-destructive Digital Indicating Tester (PUNDIT) was used in accordance with the ASTM C597 standard to perform this test. PUNDIT is equipped with two transducers with a $50 \mathrm{~mm}$ diameter that are capable of creating pulses of $54 \mathrm{kHz}$ frequency and can be used to test specimens with a minimum length of $50 \mathrm{~mm}$. According to the above-mentioned standard, the test surfaces were first stained with grease, and then pulse pass time was measured using PUNDIT by placing the transducers on them and propagating the ultrasonic pulse. Since all of the specimens (cubic, cylindrical, and beam) in this research were tested before fracture, the pulse velocity could be calculated by dividing the specimen length by the pulse pass time. Also, dynamic modulus of elasticity of the mixtures is calculated by measuring the density of cubic specimens and using Eq. (3).

$$
U P V=\sqrt{\frac{E_{\mathrm{d}}}{\rho} \times \frac{\left(1-v_{\mathrm{d}}\right)}{\left(1+v_{\mathrm{d}}\right)\left(1-2 v_{\mathrm{d}}\right)}}
$$

In this equation, $U P V$ is the ultrasonic pulse velocity $(\mathrm{m} / \mathrm{s}), \rho$ is the density $\left(\mathrm{kg} / \mathrm{m}^{3}\right), E_{\mathrm{d}}$ is the dynamic modulus of elasticity $(\mathrm{GPa})$, and 
$v_{\mathrm{d}}$ is the dynamic Poisson's ratio. Qasrawi and Marie showed that the beginning moment of cracking could be specified by measuring UPV in cubic specimens during the compressive strength test and plotting the normalized curve of the pulse velocity against compressive stress (Qasrawi and Marie, 2003). In this research, to assess the effects of RAP as coarse aggregates in RCC mixtures, on crack propagation of the mixtures, this test was performed on the specimens.

\subsubsection{Density and water absorption}

Water absorption of the concrete mixtures is a durability indicator, and by measuring it, the durability of the mixture in harsh environments can be assessed. The density and water absorption amounts of each mixture were calculated by measuring the immersed, saturated and dry masses of three cubic specimens in 28 days of age, according to ASTM C642 standard.

\subsubsection{Electrical resistivity}

Electrical resistivity is an intrinsic characteristic of materials defined as their resistance to electrical current under a unit of potential difference, and its value is equal to the reverse of electrical conductivity. Performing an electrical resistivity test in accordance with ASTM C1760 is an evaluation method of the concrete resistance to chloride ion penetration. This test is, in fact, a substitute for the ASTM C1202 test method which is time-consuming and requires more equipment. In this research, cylindrical specimens with $100 \mathrm{~mm} \times 200 \mathrm{~mm}$ dimensions were subject to a specific potential difference in 7, 28, and 90 days of age, according to ASTM C1760, and the passing current was measured. Finally, the electrical resistivity of the specimens was calculated using Eq. (4). In this equation, $V$ is the applied potential difference (V), $I$ is the passing current (A), $A$ is the area of the specimen cross-section $\left(\mathrm{m}^{2}\right)$, $L$ is the specimen's length (m), and $R$ is the electrical resistivity of the specimen $(\Omega \cdot \mathrm{m})$.

$$
R=\frac{V}{I} \times \frac{A}{L}
$$




\section{Test results}

\subsection{Compressive strength}

As shown in Fig. 7, increasing the amount of RAP in the mixtures causes the compressive strength of the mixtures to drop, which can be attributed to the weak asphalt layer on RAP material surface. The most significant decrease in the compressive strength of the mixtures compared to the control ones is more than $60 \%$, which occurred in the mixture containing $100 \%$ of coarse-grained RAP at the age of 28 days. The aged asphalt layer causes the crack path to be led around the RAP materials, which can cause the specimens to rupture under lower stresses. Also, it can be seen that increasing the curing duration of mixtures causes their strength to increase, which is due to the development in the cement hydration and creation of more amounts of hard products of these reactions (such as C-S-H). By comparing the compressive strengths of concrete mixtures containing different amounts of coarse RAP at different curing times, it is observed that the highest increase in strength occurred in the 90-day control mixtures (approximately 33\% increase in strength compared to 7-day mixtures). This difference can be attributed to the absorption of more water by the stone aggregates than the RAP materials and, as a result, more hydration of the hardened cement paste inside the concrete.

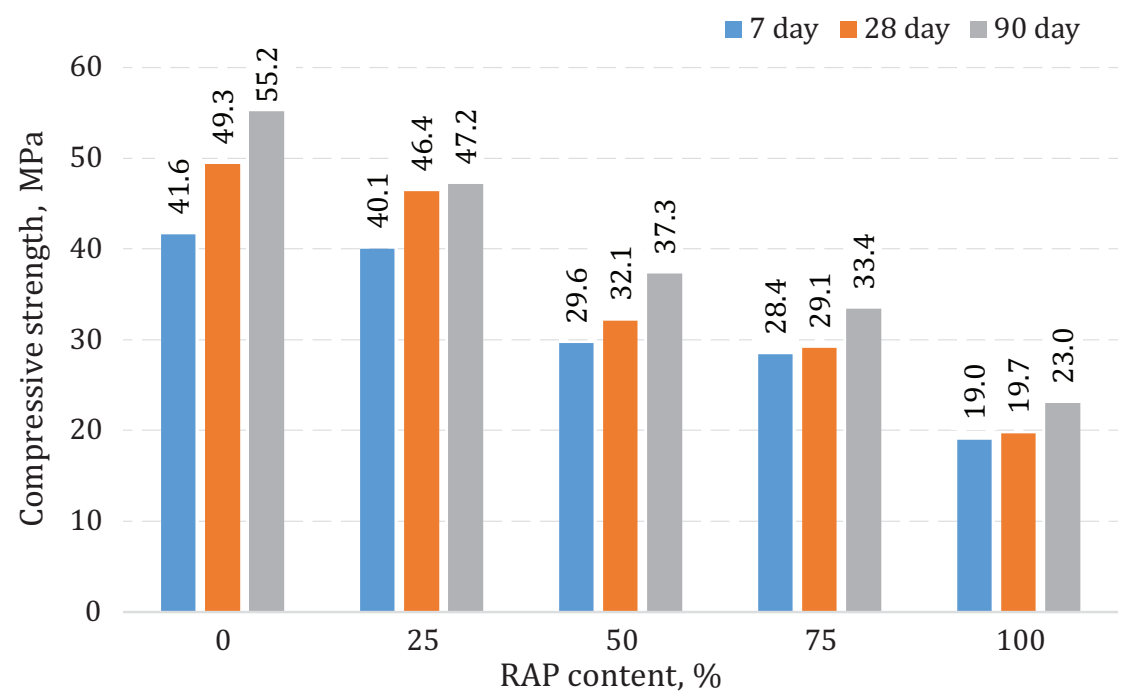

Figure 7. Compressive strength of mixtures containing different amounts of RAP
Mohammad Dareyni

Durability and

Mechanical Properties

of Roller Compacted

Concrete Containing

Coarse Reclaimed

Asphalt Pavement 


\subsection{Flexural strength}

The adhesion between the cement paste and aggregates is critically important since the bottom surface of a concrete specimen will be subject to tensile stresses under bending moment. The aged asphalt layer around the RAP materials deforms under lower stresses, which causes the flexural strength of the mixtures to drop with higher amounts of RAP since a weak area in the cross-section subject to loads leads the path of the cracks around itself. Figure 8 shows the results of the flexural strength test at different ages. The mixture containing $100 \%$ coarse RAP at the age of 7 days showed the highest decrease in flexural strength compared to the control mixture (approximately 50\% reduction in strength). Although the increase in flexural strength due to curing (90day mixtures compared to 7 days) in the concrete mixture containing $100 \%$ RAP is about $6 \%$ higher than the control mixture, the control one revealed significantly higher strength than other mixtures. This can be due to the higher water absorption of the stone aggregates and a faster hydration process in this mixture.

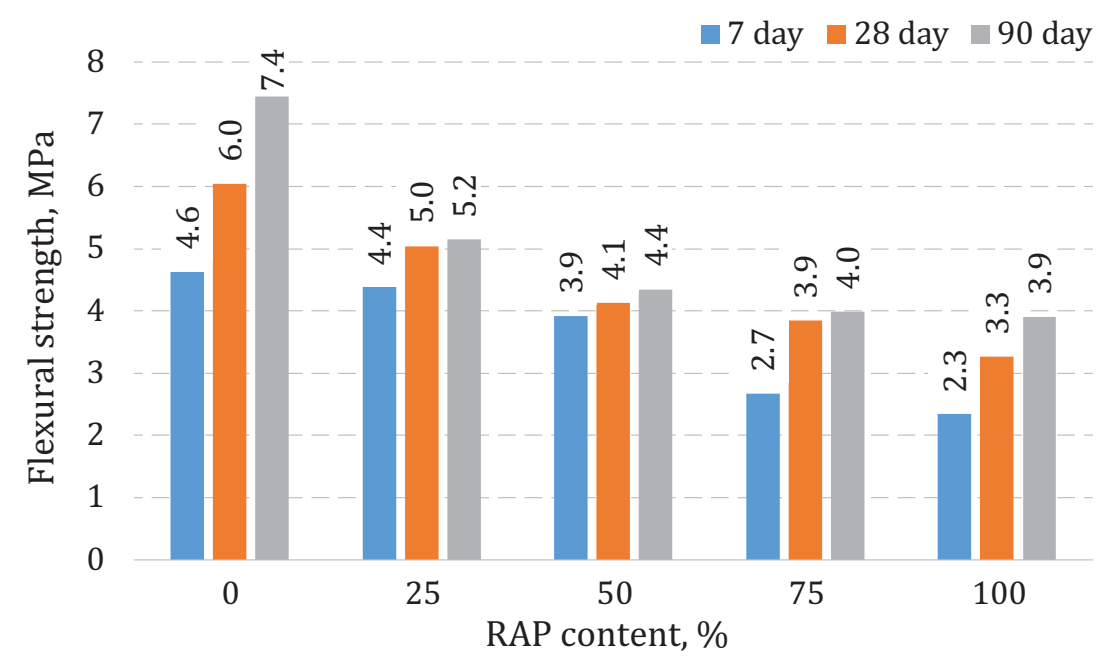

Figure 8. Flexural strength of the mixtures containing RAP at different ages 


\subsection{Splitting tensile strength}

Mohammad Dareyni

The fracture section of the cylindrical specimens subject to splitting tensile strength shows the presence of RAP materials in the fracture plane (Fig. 9). Also, according to Fig. 10, it is evident that increasing the curing age of mixtures has increased their tensile strength due to further development of hydration reactions. Similarly, it is observed that the highest increase in the tensile strength happened in the control mixture (approximately 39\% increase in the tensile strength of the 90-day mixture compared to the 7-day). Likewise, the highest drop in the tensile strength compared to the control mixture was revealed in the mixture containing $100 \%$ RAP at 28 days, which was about $45 \%$.
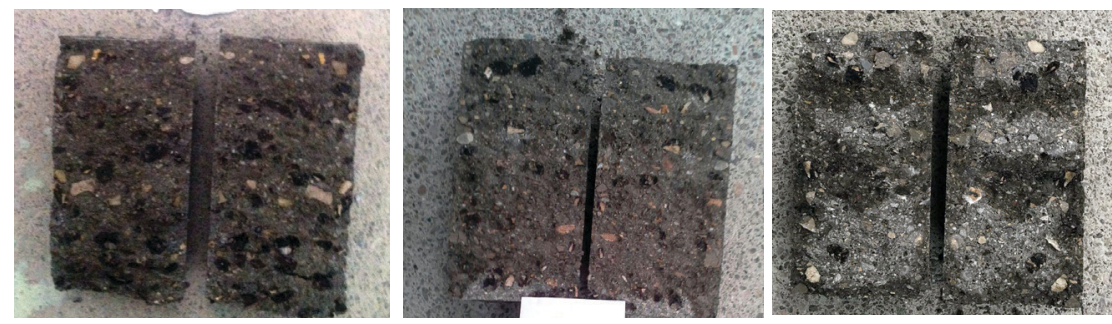

Figure 9. Fracture section of tensile specimens for mixtures R100 (left), R75 (middle), and R50 (right)

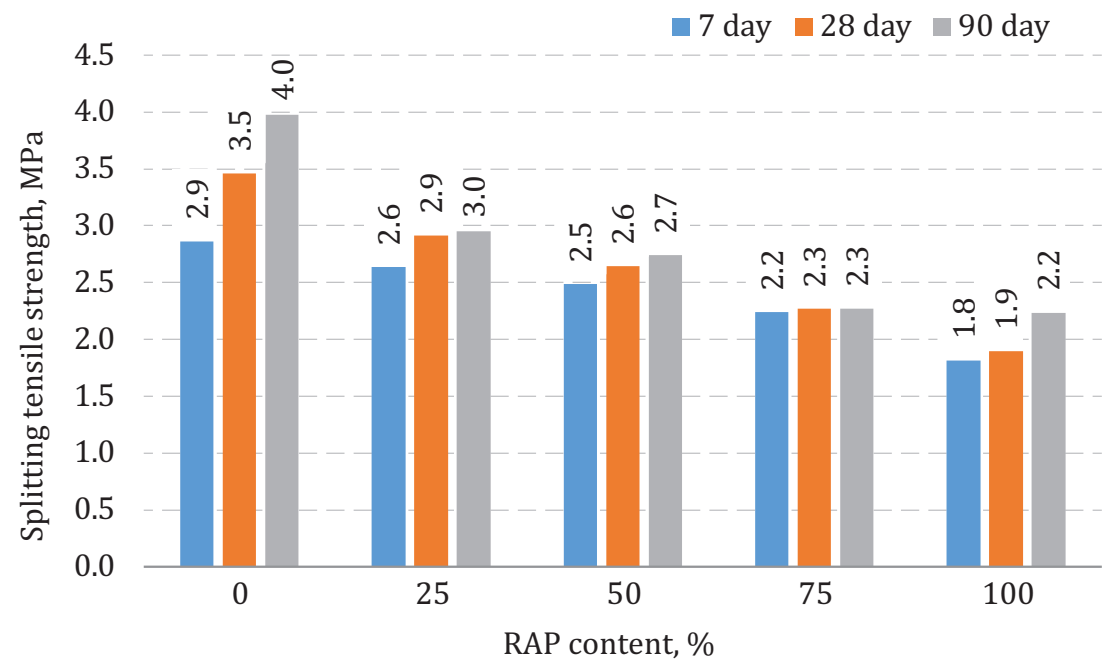

Figure 10. Splitting tensile strength of the mixtures containing RAP at different ages 


\subsection{Ultrasonic pulse velocity}

\subsubsection{Dynamic modulus of elasticity}

Results of the UPV test indicated that using RAP in RCC mixtures can decrease their dynamic modulus of elasticity. Since the stiffness of materials is a highly influential factor in their dynamic modulus of elasticity, the decreased modulus of the mixtures containing RAP can be due to their decreased stiffness. The asphalt on the surface of RAP materials has lower stiffness than other materials in the concrete; therefore, its presence reduces the stiffness of the mixtures. Figure 11 shows the values of the dynamic modulus for mixtures containing different amounts of RAP at different ages. It can be seen that increasing the curing age for mixtures caused their dynamic modulus to increase, which could be due to the increased stiffness as a result of more developed hydration reactions.

\subsubsection{Estimation of strength regression models}

The UPV test was performed on all specimens at all ages before performing compressive, flexural, and tensile strength tests, and its results were employed to develop the strength estimation model for the mixtures. Figures 12 to 14 show these models and Table 4 presents their characteristics. The highest coefficient of determination $\left(R^{2}\right)$

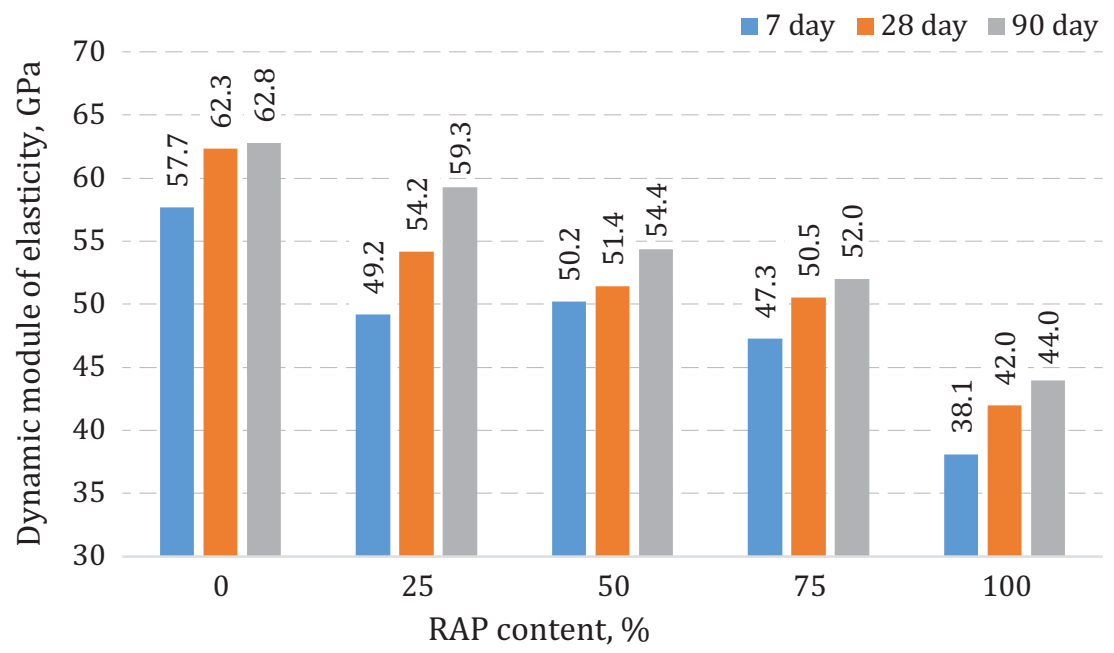

Figure 11. Dynamic modulus of elasticity of mixtures containing different amounts of RAP 
is observed by the results of the control mixture, which is due to higher homogeneity of these mixtures in terms of the properties of the materials employed in their manufacturing. It is also observed that, in general, $R^{2}$ of the estimated compressive strength models are higher than those of the flexural and tensile strength. This can be attributed to the different crack paths in the flexural strength (crack initiations from the lower beams) and the tensile strength (cracks in the loaded plate) tests. However, in the compressive strength test, cracks begin to initiate from weaker zones of the specimen. Therefore, the results of the flexural and tensile strength of mixtures are more affected by the local characteristics of the mixture. On the other hand, the ultrasonic wave always traverses the sample via the path with the most solidity, which is not necessarily either the lower beams of the sample or the loaded plate.
Alireza Mahdavi, Abolfazl

Mohammadzadeh

Moghaddam,

Mohammad Dareyni

Durability and Mechanical Properties of Roller Compacted Concrete Containing Coarse Reclaimed Asphalt Pavement

Table 4. Characteristics of the models for mechanical properties of the RCC mixtures

\begin{tabular}{cccc}
\hline Mix. & Compressive strength & Flexural strength & Splitting tensile strength \\
\hline R0 & $f_{\mathrm{c}}=0.224 \mathrm{e}^{0.0010 \mathrm{~V}}\left(R^{2}=0.92\right)$ & $f_{\mathrm{r}}=0.323 \mathrm{e}^{0.0006 \mathrm{~V}}\left(R^{2}=0.87\right)$ & $f_{\mathrm{t}}=0.151 \mathrm{e}^{0.0006 \mathrm{~V}}\left(R^{2}=0.83\right)$ \\
$\mathbf{R} 25$ & $f_{\mathrm{c}}=2.449 \mathrm{e}^{0.0006 \mathrm{~V}}\left(R^{2}=0.76\right)$ & $f_{\mathrm{r}}=0.476 \mathrm{e}^{0.0005 \mathrm{~V}}\left(R^{2}=0.58\right)$ & $f_{\mathrm{t}}=0.015 \mathrm{e}^{0.0011 \mathrm{~V}}\left(R^{2}=0.52\right)$ \\
$\mathbf{R}$ 0 & $f_{\mathrm{c}}=0.074 \mathrm{e}^{0.0013 \mathrm{~V}}\left(R^{2}=0.69\right)$ & $f_{\mathrm{r}}=0.363 \mathrm{e}^{0.0005 \mathrm{~V}}\left(R^{2}=0.74\right)$ & $f_{\mathrm{t}}=0.267 \mathrm{e}^{0.0005 \mathrm{~V}}\left(R^{2}=0.81\right)$ \\
$\mathbf{R 7 5}$ & $f_{\mathrm{c}}=1.416 \mathrm{e}^{0.0006 \mathrm{~V}}\left(R^{2}=0.56\right)$ & $f_{\mathrm{r}}=0.014 \mathrm{e}^{0.0012 \mathrm{~V}}\left(R^{2}=0.60\right)$ & $f_{\mathrm{t}}=1.293 \mathrm{e}^{0.0001 \mathrm{~V}}\left(R^{2}=0.65\right)$ \\
$\mathbf{R} 100$ & $f_{\mathrm{c}}=4.137 \mathrm{e}^{0.0004 \mathrm{~V}}\left(R^{2}=0.66\right)$ & $f_{\mathrm{r}}=0.051 \mathrm{e}^{0.0010 \mathrm{~V}}\left(R^{2}=0.66\right)$ & $f_{\mathrm{t}}=0.360 \mathrm{e}^{0.0004 \mathrm{~V}}\left(R^{2}=0.55\right)$ \\
\hline
\end{tabular}

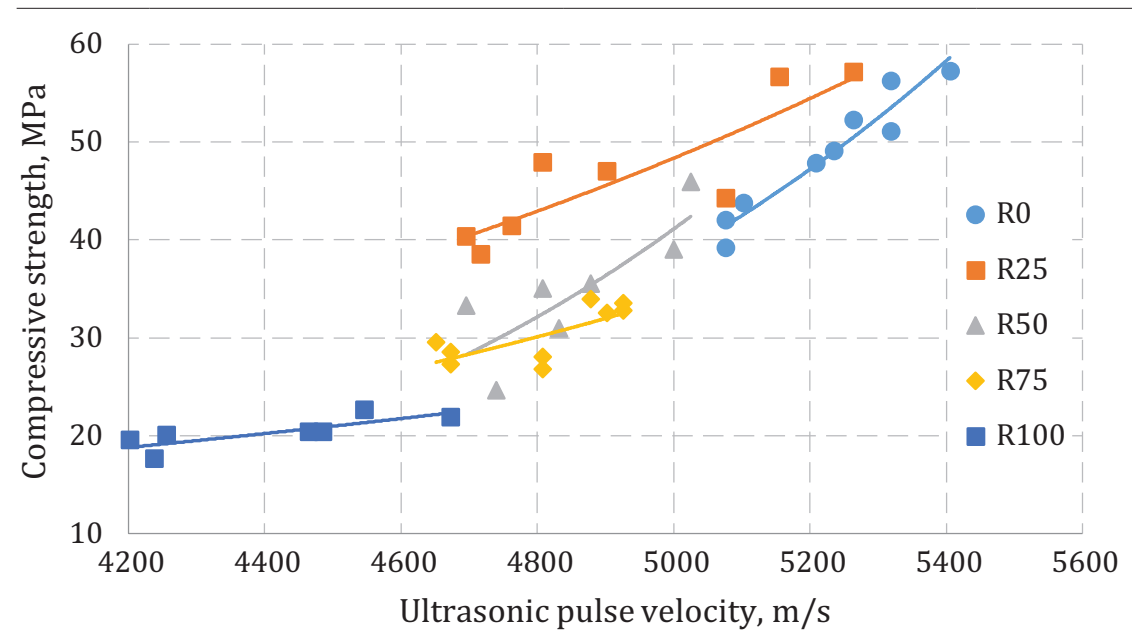

Figure 12. Compressive strength-UPV curves 


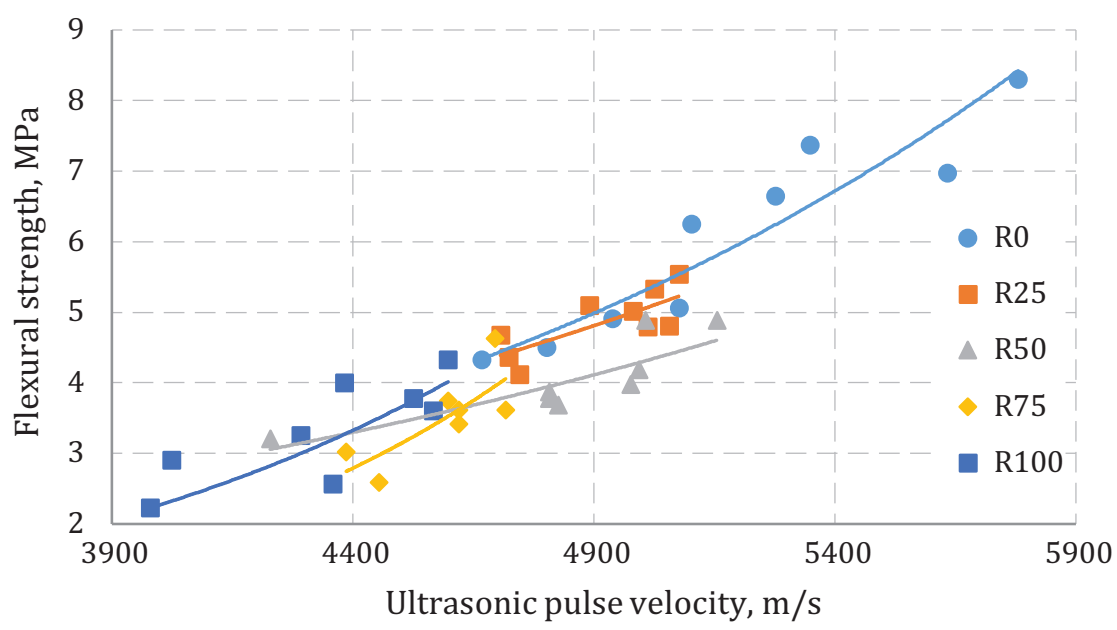

Figure 13. Flexural strength-UPV curves

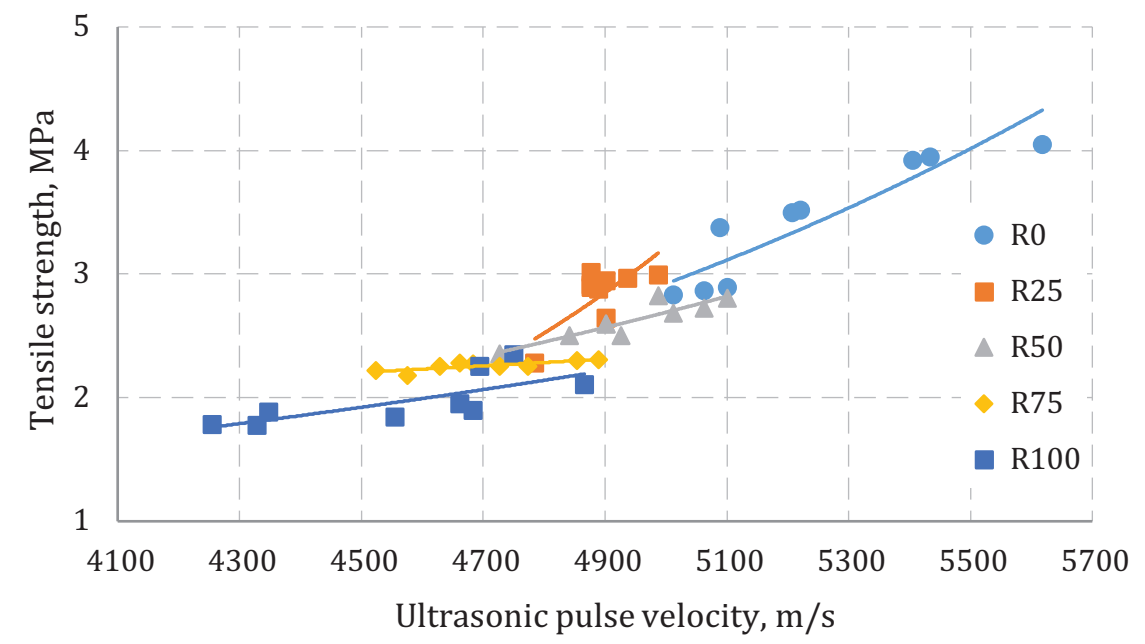

Figure 14. Tensile strength-UPV curves

\subsubsection{Crack propagation}

Fracture of the specimens subject to compressive stress occurs when the micro-cracks develop and join in the specimen. The crack propagation speed in loaded specimens is critical, since this characteristic of the concrete is affected by its ductility. Higher crack propagation speed in the concrete leads to more brittle fracture and 
less ductility (Marie, 2016). On the other hand, UPV is highly sensitive to the presence of cracks in the material, and with more numbers and higher width of the cracks, the UPV decreases. Thus, Fig. 15 was plotted by measuring the UPV in cubic specimens subject to compressive stresses until the fracture moment. This figure shows the UPV lines (as a percentage of the unloaded specimen UPV) plotted against compressive stress (as a percentage of the specimen final compressive strength).

It is noticeable that increasing the compressive stress up to a point has no effect on the UPV in the loaded specimen, and after that point, causes the UPV to drop. This velocity drop means that micro-cracks are formed in the specimen, and increasing the compressive stress further will increase the number and width of these micro-cracks, and therefore, lead to larger drops in the UPV. Qasrawi and Marie showed that when the UPV reached $94 \%$ of its initial value in a cubic specimen under compressive stress, crack propagation would begin (Qasrawi and Marie, 2003). The horizontal line in Fig. 15 was also drawn for 94\% of the initial amount of UPV. It is evident that by increasing the amount of RAP in the mixtures, the intersection of the crack propagation lines with the horizontal line moves towards the left. This intersection divides the load bearing of the specimen into "before cracking" and "after cracking" phases. Figure 16 shows the load-bearing percentage of each RCC mixture after the cracking phase. As illustrated, by increasing the amount of RAP in the RCC mixture and moving the cracking point towards the left, the load-bearing percentage in the after-cracking phase will increase. This change in the crack propagation pattern of the RCC

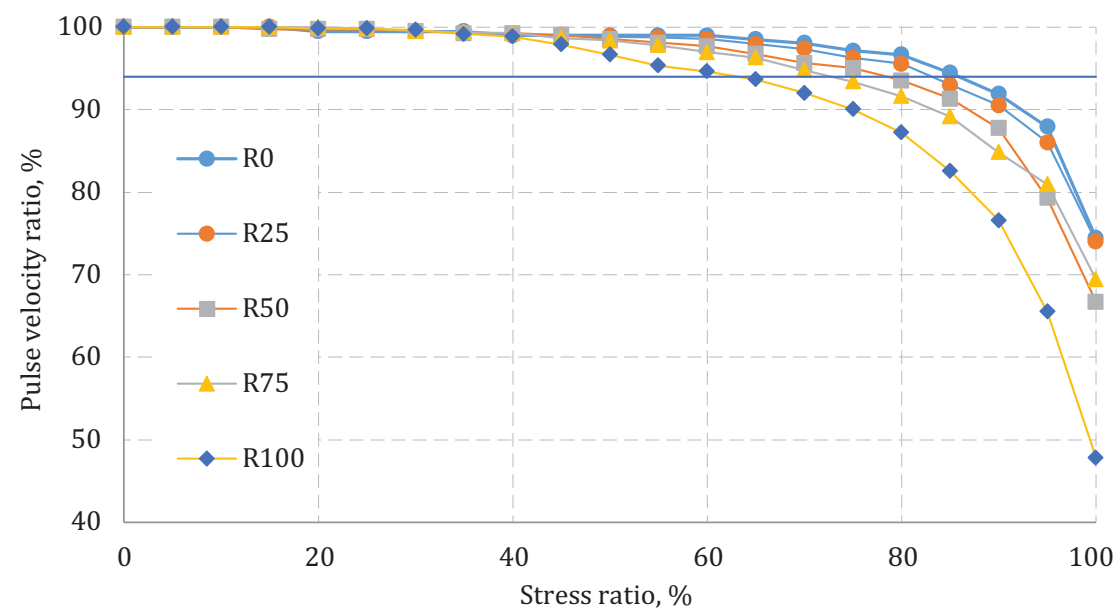

Figure 15. UPV lines against applied compressive stress in the RCC mixtures containing different amounts of RAP
Mohammad Dareyni

Durability and Mechanical Properties of Roller Compacted Concrete Containing Coarse Reclaimed Asphalt Pavement 
mixtures containing RAP can be attributed to the increased toughness in them since toughness is defined as an indicator of the load-bearing of the specimen after the cracking begins.

\subsection{Density and water absorption}

Figure 17 indicates the water absorption and density amounts for the RCC mixtures investigated in this study. As it is obvious, utilizing RAP in the mixtures has not had an effect with a specific pattern on the mixture water absorption. However, due to lower density of RAP compared with aggregates, replacing RCC coarse aggregates with RAP has decreased the density of the mixtures.

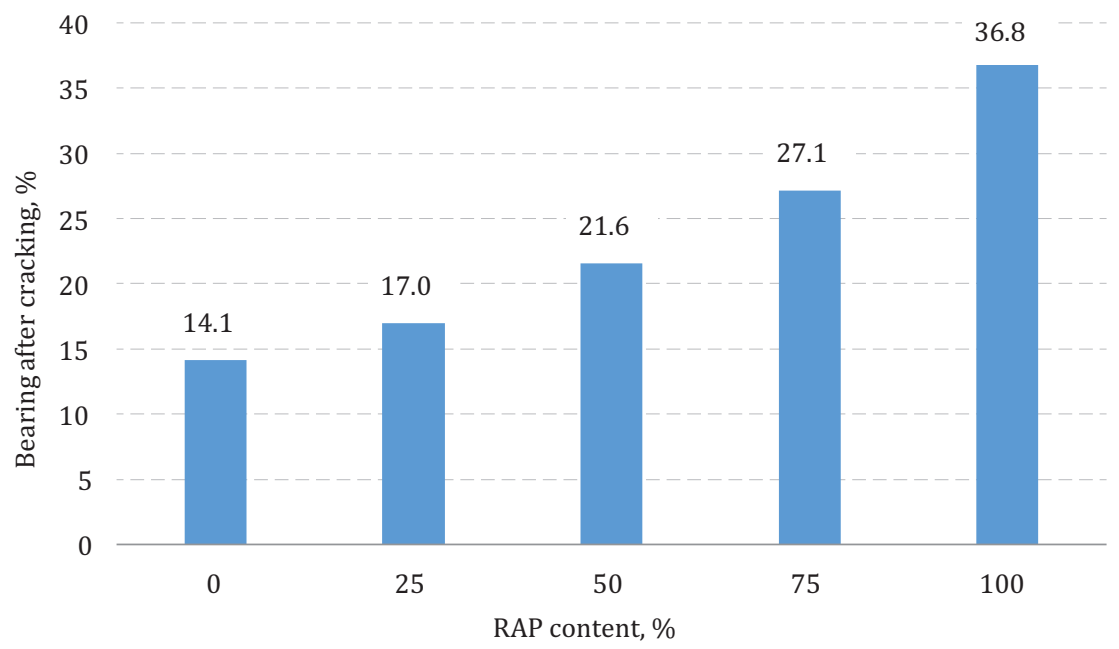

Figure 16. Load-bearing percentage of RCC mixtures containing RAP in the after-cracking phase
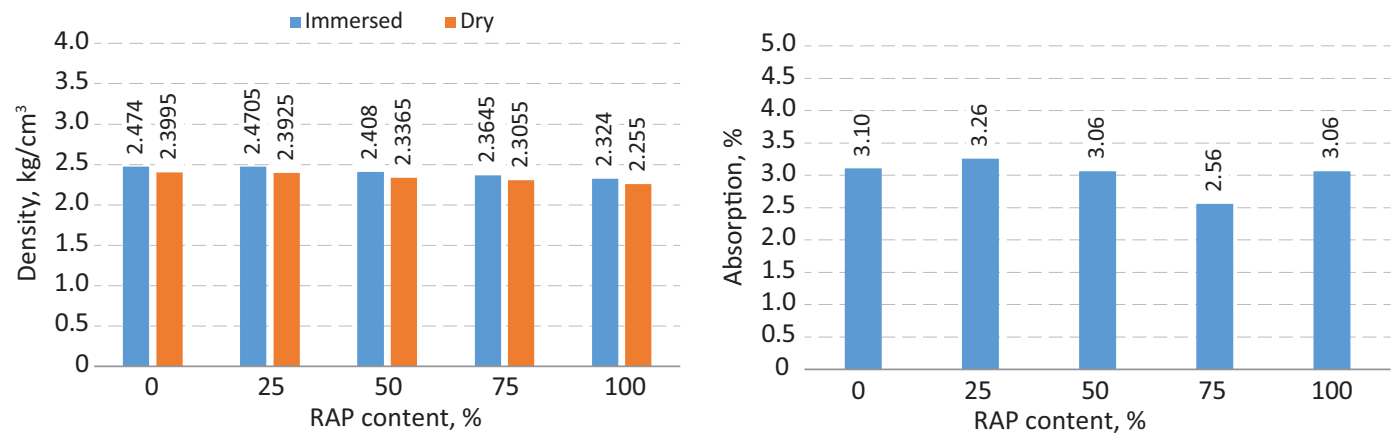

Figure 17. Density (right) and water absorption (left) of the RCC mixtures containing RAP 


\subsection{Electrical resistivity}

Mohammad Dareyni

The electrical resistivity of saturated concrete specimens is an indicator of the amount of pores and their connectivity. The higher the number of pores and their connectivity, the easier the movement of ions inside them in the saturated state, and, therefore, the less their electrical resistivity. In general, Fig. 18 shows that increasing the amount of RAP in the mixtures increased their electrical resistivity. This increase in the electrical resistivity can be caused by the decrease in the amount of pores or can be caused by the properties of RAP materials. Nevertheless, since the results of the water absorption test (which is an indicator of the amount of concrete pores) do not show a decreasing trend, it can be concluded that the number of pores in the mixture is not considerably affected by the presence of RAP materials. Therefore, the increased electrical resistivity of the mixture can only be due to the properties of RAP materials. The particular property of RAP materials that makes them different from original aggregates is the asphalt layer on the surface of these materials. When RAP is placed in the vicinity of pores, it can prevent them from connecting with each other, since H. Schubert has shown that the more hydrophobic materials form a larger connection angle with water which reduces their connection surface with water (Schubert, 1984). This reduced connection surface can prevent pores from connecting to each other in some cases (Fig. 19).

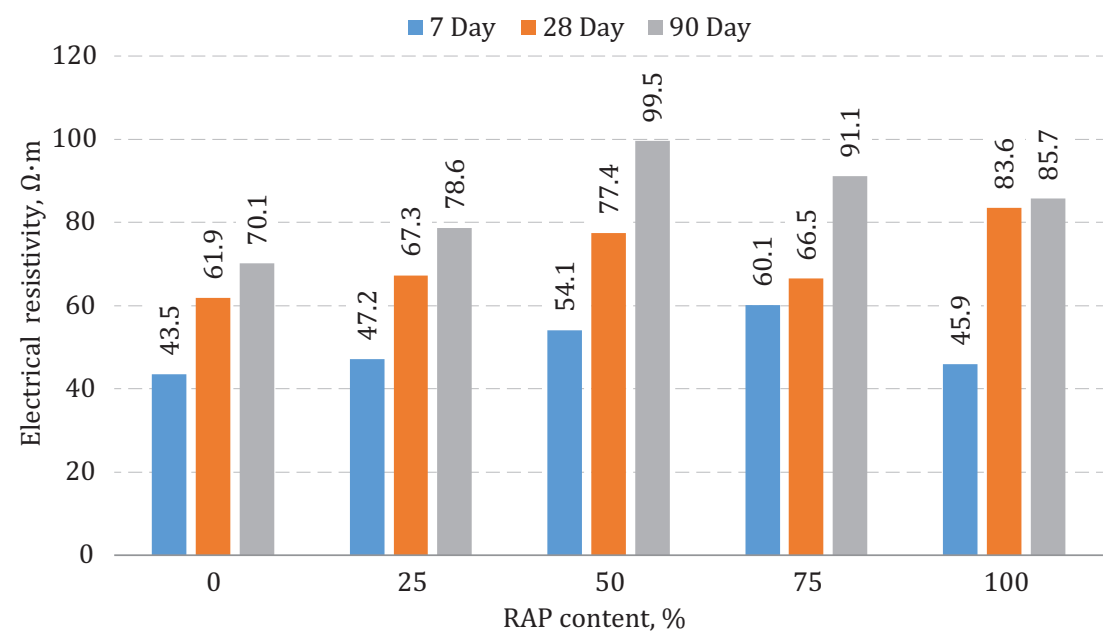

Figure 18. Electrical resistivity of the mixtures containing different amounts of RAP 
It is also observed that changes in the electrical resistivity of the mixtures are associated with the peak points, which vary at different curing ages by RAP contents. The presence of these peaks can indicate the impact of RAP aggregates on the development of cement hydration. This impact can be manifested by leaving pores within the mixture owing to preventing sufficient water from reaching the cement paste around the RAP aggregates and thereby incomplete or retarded cement hydration in the course of curing age. These pores, in turn, would lead to a variation in the electrical resistivity at different curing ages and RAP contents.

\subsection{Analysis of variance}

The difference between the results of different RCC mixtures including RAP in different tests may be caused by random errors in lab procedures. Therefore, a two-way analysis of variance was performed at a $95 \%$ confidence level to clarify the significance or insignificance of these differences. According to Table 5, it is clear that the difference caused by curing age and the amount of RAP in compressive, flexural and tensile strength, dynamic modulus, and electrical resistivity test is significant and not random, i.e., these properties are affected by the amount of RAP in the RCC mixtures. Also, due to 28 days of age of specimens in the crack propagation test, analysis of variance performed on the result of this test was one-way, which showed that the amount of RAP had a significant effect on the cracking pattern of the RCC mixtures.
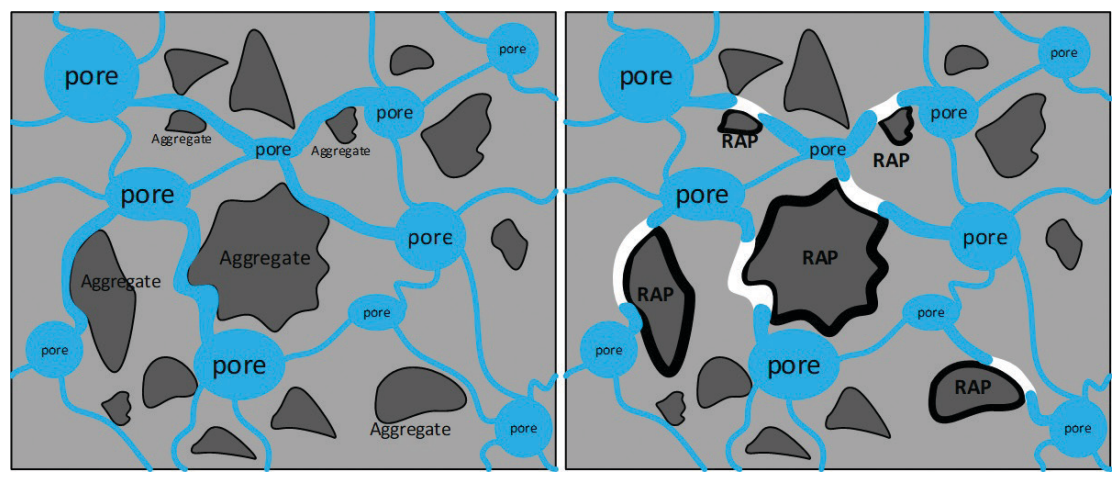

Figure 19. A comparison between the connectivity of pores in mixtures without RAP (left) and containing RAP (right) 
Table 5. Analysis of variance of the test results

\begin{tabular}{|c|c|c|c|c|c|c|}
\hline Test & Source & DF & Adj SS & Adj MS & F-Value & $P$-Value \\
\hline \multirow{5}{*}{$\begin{array}{c}\text { Compressive } \\
\text { strength }\end{array}$} & $\begin{array}{c}\text { RAP } \\
\text { content }\end{array}$ & 4 & 4608 & 1152 & 37.54 & 0.000 \\
\hline & Age & 2 & 418 & 209 & 6.81 & 0.004 \\
\hline & Interaction & 8 & 114 & 14 & 0.46 & 0.872 \\
\hline & Error & 30 & 921 & 31 & & \\
\hline & Total & 44 & 6060 & & & \\
\hline \multirow{5}{*}{$\begin{array}{l}\text { Flexural } \\
\text { strength }\end{array}$} & $\begin{array}{c}\text { RAP } \\
\text { content }\end{array}$ & 4 & 11 & 3 & 171.87 & 0.000 \\
\hline & Age & 2 & 1 & 1 & 41.82 & 0.000 \\
\hline & Interaction & 8 & 1 & 0 & 8.14 & 0.000 \\
\hline & Error & 30 & 0 & 0 & & \\
\hline & Total & 44 & 14 & & & \\
\hline \multirow{5}{*}{$\begin{array}{l}\text { Splitting tensile } \\
\text { strength }\end{array}$} & $\begin{array}{c}\text { RAP } \\
\text { content }\end{array}$ & 4 & 47 & 12 & 31.98 & 0.000 \\
\hline & Age & 2 & 15 & 7 & 19.72 & 0.000 \\
\hline & Interaction & 8 & 5 & 1 & 1.83 & 0.111 \\
\hline & Error & 30 & 11 & 0 & & \\
\hline & Total & 44 & 78 & & & \\
\hline \multirow{5}{*}{$\begin{array}{l}\text { Electrical } \\
\text { resistivity }\end{array}$} & $\begin{array}{c}\text { RAP } \\
\text { content }\end{array}$ & 4 & 2043 & 511 & 27.98 & 0.000 \\
\hline & Age & 2 & 4627 & 2313 & 126.74 & 0.000 \\
\hline & Interaction & 8 & 586 & 73 & 4.01 & 0.002 \\
\hline & Error & 30 & 548 & 18 & & \\
\hline & Total & 44 & 7803 & & & \\
\hline \multirow{5}{*}{$\begin{array}{l}\text { Dynamic } \\
\text { modulus }\end{array}$} & $\begin{array}{c}\text { RAP } \\
\text { content }\end{array}$ & 4 & 1813 & 453 & 151 & 0.000 \\
\hline & Age & 2 & 356 & 178 & 59 & 0.000 \\
\hline & Interaction & 8 & 38 & 5 & 2 & 0.169 \\
\hline & Error & 30 & 90 & 3 & & \\
\hline & Total & 44 & 2297 & & & \\
\hline \multirow{3}{*}{$\begin{array}{c}\text { Crack } \\
\text { propagation }\end{array}$} & $\begin{array}{l}\text { RAP } \\
\text { content }\end{array}$ & 4 & 1039262 & 259816 & 49.61 & 0.000 \\
\hline & Error & 10 & 52368 & 5237 & & \\
\hline & Total & 14 & 1091630 & & & \\
\hline
\end{tabular}

Alireza Mahdavi,

Abolfazl

Mohammadzadeh

Moghaddam

Mohammad Dareyni

Durability and

Mechanical Properties of Roller Compacted

Concrete Containing

Coarse Reclaimed

Asphalt Pavement 


\section{Conclusion and suggestions}

- Utilizing RAP in manufacturing RCC caused its mechanical properties to drop significantly, at the 95\% confidence level, which was highest in the compressive strength test results, such that, in a mixture containing 100\% coarse RAP, a 61\% strength reduction was observed compared with the control specimen. However, since the minimum 28-day compressive strength determined for RCC mixtures by the regulations is $27.6 \mathrm{MPa}$, RAP can be used as a replacement for $75 \%$ of coarse aggregates maximum. This maximum is suggested for a concrete mixture with $300 \mathrm{~kg} / \mathrm{m}^{3}$ cement, and further experimental investigations are required for different types of concrete to determine the allowable limit of RAP to be used.

- The significant decrease ( $p$-value $<0.05)$ in the dynamic modulus of mixtures is considered a weakness for concrete used for pavement purposes. Regarding the dynamic nature of the pavement loads, the dynamic modulus is an important characteristic in them, which is reduced by increasing the amount of RAP. However, it must be noted that the specific equation used for homogenous and isotropic materials was used to calculate this value which reduced the accuracy of the results. However, this method is typical for estimating the dynamic modulus of concrete.

- Strength estimation models can be used for estimating the strength of the mixtures because of their proper $R^{2}$ value. However, the coefficients of these models must be calibrated for different mixture proportions, which requires manufacturing lab specimens and performing tests on them.

- Monitoring the cracking process of the specimens under loading can provide beneficial information regarding the effects of materials on the mixture fracture properties. Investigating the results of this test shows that using RAP can significantly change the cracking pattern of the mixtures and increase their toughness ( $p$-value <0.05).

- Water absorption variations with the increased amount of RAP have followed no specific pattern. However, since this characteristic of concrete directly affects its durability in harsh environments, further studies are required regarding the durability indicators of concrete containing RAP.

- Electrical resistivity test is a non-destructive method of assessing the durability of mixtures which can highly reduce the cost of lab experiments. Generally, there is a correlation between the results of this test and other durability-related tests on the RCC 
mixtures. Nevertheless, enough consideration is required in using the present models due to the presence of asphalt around RAP materials.

- Increasing the amount of RAP in the RCC mixtures increased their electrical resistivity ( $p$-value < 0.05). Hydrophobicity of aged asphalt in RAP materials probably decreases the connectivity of the pores and consequently improves the durability of RCC mixtures.

\section{Future research}

Utilizing RAP as waste material in the concrete has favourable environmental results, and the strength reduction due to using these materials should not lead to putting these materials aside. Rather, this strength reduction can be minimised by employing admixtures and complementary cementitious materials. Also, comparing the results of this research with similar studies, it is evident that pre-processing by impact and abrasion can be effective in reducing the strength drop of the mixtures containing RAP. However, considering the different methods proposed for this purpose, further studies must be performed to standardise these operations.

\section{Acknowledgement}

The authors would like to express their gratitude to laboratory technicians (Mr. Hajinezhad and Fanoudi), and Mr. Bazghandi for their help in laboratory management.

\section{REFERENCES}

Abdel-Mohti, A., Shen, H., Khodair, Y. (2016). Characteristics of self-consolidating concrete with RAP and SCM. Construction and Building Materials, 102, 564-573. https://doi.org/10.1016/j.conbuildmat.2015.11.007

ACI (1995). ACI 325.10R-95: Report on Roller-Compacted Concrete Pavements. American Concrete Institute, p. 32.

Al-Mufti, R. L., Fried, A. N. (2017). Improving the strength properties of recycled asphalt aggregate concrete. Construction and Building Materials, 149, 45-52. https://doi.org/10.1016/j.conbuildmat.2017.05.056

Bilodeau, K., Sauzeat, C., Di Benedetto, H., Olard, F., Bonneau, D. (2011). Laboratory and In Situ Investigations of Steel Fiber-Reinforced Compacted
Mohammad Dareyni

Durability and Mechanical Properties of Roller Compacted Concrete Containing Coarse Reclaimed Asphalt Pavement 
Concrete Containing Reclaimed Asphalt Pavement. In Transportation Research Board 90th Annual Meeting. Washington DC, U.S.

Erdem, S., Blankson, M. A. (2014). Environmental performance and mechanical analysis of concrete containing recycled asphalt pavement (RAP) and waste precast concrete as aggregate. Journal of Hazardous Materials, 264, 403-410. https://doi.org/10.1016/j.jhazmat.2013.11.040

Fakhri, M., Amoosoltani, E. (2017). The effect of Reclaimed Asphalt Pavement and crumb rubber on mechanical properties of Roller Compacted Concrete Pavement. Construction and Building Materials, 137, 470-484. https://doi.org/10.1016/j.conbuildmat.2017.01.136

Ferrebee, E., Brand, A., Kachwalla, A., Roesler, J., Gancarz, D., Pforr, J. (2014). Fracture Properties of Roller-Compacted Concrete with Virgin and Recycled Aggregates. Transportation Research Record: Journal of the Transportation Research Board, 2441, 128-134. https://doi.org/10.3141/2441-17

Harrington, D., Abdo, F., Adaska, W., V.Hazaree, C., Ceylan, H. (2010). Guide for Roller-Compacted Concrete Pavements. In Trans Project Reports. Iowa State University.

Huang, B., Shu, X., Li, G. (2005). Laboratory investigation of portland cement concrete containing recycled asphalt pavements. Cement and Concrete Research, 35(10), 2008-2013.

https://doi.org/10.1016/j.cemconres.2005.05.002

Jamshidi, A., Hamzah, M. O., Shahadan, Z. (2012). Selection of reclaimed asphalt pavement sources and contents for asphalt mix production based on asphalt binder rheological properties, fuel requirements and greenhouse gas emissions. Journal of Cleaner Production, 23(1), 20-27.

https://doi.org/10.1016/j.jclepro.2011.10.008

Kar, S. S., Swamy, A. K., Tiwari, D., Jain, P. K. (2018). Impact of recycled asphalt pavement on properties of foamed bituminous mixtures. Baltic Journal of Road and Bridge Engineering, 13(1), 14-22. https://doi.org/10.3846/bjrbe.2018.383

Khodair, Y., Luqman. (2017). Self-compacting concrete using recycled asphalt pavement and recycled concrete aggregate. Journal of Building Engineering, 12, 282-287. https://doi.org/10.1016/j.jobe.2017.06.007

Khodair, Y., Raza, M. (2017). Sustainable self-consolidating concrete using recycled asphalt pavement and high volume of supplementary cementitious materials. Construction and Building Materials, 131, 245-253.

https://doi.org/10.1016/j.conbuildmat.2016.11.044

Kriz, P., Grant, D. L., Veloza, B. A., Gale, M. J., Blahey, A. G., Brownie, J. H., Shirts, R. D., Maccarrone, S. (2014). Blending and diffusion of reclaimed asphalt pavement and virgin asphalt binders. Road Materials and Pavement Design, 15(sup1), 78-112. https://doi.org/10.1080/14680629.2014.927411

Marie, I. (2016). Zones of weakness of rubberized concrete behavior using the UPV. Journal of Cleaner Production, 116, 217-222. https://doi.org/10.1016/j.jclepro.2015.12.096

Mathias, V., Sedran, T., de Larrard, F. (2009). Modelling of Mechanical Properties of Cement Concrete Incorporating Reclaimed Asphalt Pavement. Road Materials and Pavement Design, 10(1), 63-82. 
https://doi.org/10.1080/14680629.2009.9690182

Modarres, A., Hosseini, Z. (2014). Mechanical properties of roller compacted concrete containing rice husk ash with original and recycled asphalt pavement material. Materials \& Design, 64, 227-236.

https://doi.org/10.1016/j.matdes.2014.07.072

Niazi, Y., Jalili, M. (2009). Effect of Portland cement and lime additives on properties of cold in-place recycled mixtures with asphalt emulsion. Construction and Building Materials, 23(3), 1338-1343. https://doi.org/10.1016/j.conbuildmat.2008.07.020

Qasrawi, H. Y., Marie, I. A. (2003). The use of USPV to anticipate failure in concrete under compression. Cement and Concrete Research, 33(12), 2017-2021. https://doi.org/10.1016/S0008-8846(03)00218-7

Rahman, M. A., Imteaz, M., Arulrajah, A., Disfani, M. M. (2014). Suitability of recycled construction and demolition aggregates as alternative pipe backfilling materials. Journal of Cleaner Production, 66, 75-84. https://doi.org/10.1016/j.jclepro.2013.11.005

Saberi.K, F., Fakhri, M., Azami, A. (2017). Evaluation of warm mix asphalt mixtures containing reclaimed asphalt pavement and crumb rubber. Journal of Cleaner Production, 165, 1125-1132. https://doi.org/10.1016/j.jclepro.2017.07.079

Schubert, H. (1984). Capillary forces - modeling and application in particulate technology. Powder Technology, 37(1), 105-116. https://doi.org/10.1016/0032-5910(84)80010-8

Settari, C., Debieb, F., Kadri, E. H., Boukendakdji, O. (2015). Assessing the effects of recycled asphalt pavement materials on the performance of roller compacted concrete. Construction and Building Materials, 101(P1), 617-621. https://doi.org/10.1016/j.conbuildmat.2015.10.039

Shi, X., Mukhopadhyay, A., Liu, K.-W. (2017). Mix design formulation and evaluation of portland cement concrete paving mixtures containing reclaimed asphalt pavement. Construction and Building Materials, 152, 756-768. https://doi.org/10.1016/j.conbuildmat.2017.06.174

Singh, S., Ransinchung, G. D., Kumar, P. (2017). Effect of mineral admixtures on fresh, mechanical and durability properties of RAP inclusive concrete. Construction and Building Materials, 156, 19-27. https://doi.org/10.1016/j.conbuildmat.2017.08.144

Singh, S., Ransinchung, G. D. R. N., Monu, K., Kumar, P. (2018). Laboratory investigation of RAP aggregates for dry lean concrete mixes. Construction and Building Materials, 166, 808-816. https://doi.org/10.1016/j.conbuildmat.2018.01.131

Stroup-Gardiner, M. (2013). Recycled Materials and Byproducts in Highway Applications-Summary Report, Volume 1. The National Academies Press. https://doi.org/10.17226/22552

Xie, Z., Tran, N., Taylor, A., Julian, G., West, R., Welch, J. (2017). Evaluation of foamed warm mix asphalt with reclaimed asphalt pavement: field and laboratory experiments. Road Materials and Pavement Design, 18(sup4), 328-352. https://doi.org/10.1080/14680629.2017.1389077
Durability and Mechanical Properties of Roller Compacted Concrete Containing Coarse Reclaimed Asphalt Pavement 
THE BALTIC JOURNAL OF ROAD AND BRIDGE ENGINEERING

$2021 / 16(3)$

Yan, Y., Roque, R., Hernando, D., Chun, S. (2019). Cracking performance characterisation of asphalt mixtures containing reclaimed asphalt pavement with hybrid binder. Road Materials and Pavement Design, 20(2), 347-366. https://doi.org/10.1080/14680629.2017.1393002 